TI 2014-132/VIII

Tinbergen Institute Discussion Paper

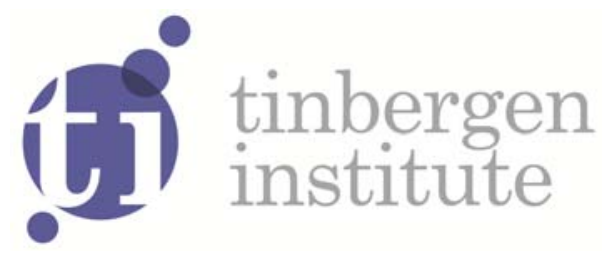

\title{
The Economics of Transboundary River Management
}

\author{
Erik Ansink
}

Harold Houba

Faculty of Economics and Business Administration, VU University Amsterdam, and Tinbergen Institute, the Netherlands 
Tinbergen Institute is the graduate school and research institute in economics of Erasmus University Rotterdam, the University of Amsterdam and VU University Amsterdam.

More TI discussion papers can be downloaded at http://www.tinbergen.nl

Tinbergen Institute has two locations:

Tinbergen Institute Amsterdam

Gustav Mahlerplein 117

1082 MS Amsterdam

The Netherlands

Tel.: +31(0)205251600

Tinbergen Institute Rotterdam

Burg. Oudlaan 50

3062 PA Rotterdam

The Netherlands

Tel.: +31(0)10 4088900

Fax: $+31(0) 104089031$

Duisenberg school of finance is a collaboration of the Dutch financial sector and universities, with the ambition to support innovative research and offer top quality academic education in core areas of finance.

DSF research papers can be downloaded at: http://www.dsf.nl/

Duisenberg school of finance

Gustav Mahlerplein 117

1082 MS Amsterdam

The Netherlands

Tel.: +31(0)20 5258579 


\title{
The economics of transboundary river management ${ }^{*}$
}

\author{
To appear as a chapter in the "Handbook of Water Economics" \\ (eds. Ariel Dinar, Kurt Schwabe), Cheltenham: Edward Elgar, 2015
}

\author{
Erik Ansink ${ }^{\dagger}$ \\ Harold Houba
}

$10 / 6 / 2014$

\begin{abstract}
We survey the economics of transboundary river water allocation, which emerged in the 1960s and has matured over the last decade due to increasing concerns over water scarcity and pollution. We outline the major approaches and pay specific attention to the strategic aspects of transboundary river water allocation. These strategic aspects are captured by employing game theory to assess the economics of transboundary river water allocation in a simple model of river sharing. This model allows us to show how conflict and cooperation over transboundary water resources may occur. It also allows us to pay specific attention to the efficiency, sustainability, and fairness of solutions to this model. We compare and contrast both cooperative and non-cooperative approaches and we relate their solutions to illustrative examples.
\end{abstract}

\section{Corresponding author:}

Erik Ansink

Department of Spatial Economics, VU University Amsterdam

De Boelelaan 1105, 1081 HV Amsterdam, the Netherlands

Email: erik.ansink@vu.nl

Tel: +31205981214

\footnotetext{
* We thank Petra Hellegers for discussions that were valuable to this chapter.

$\dagger$ Department of Spatial Economics and IVM, VU University Amsterdam, and Tinbergen Institute.

$\$$ Department of Econometrics, VU University Amsterdam, and Tinbergen Institute.
} 


\section{Introduction}

We assess a very general economic model of transboundary river water allocation and show how it has been used in the literature and how it can be applied to assess three key objectives of transboundary river management: efficiency, sustainability, and fairness. Efficiency deals with using water for its highest value use so that no gains from reallocation remain unexploited. Sustainability deals with the strategic incentives of countries to comply with some agreed water allocation schedule, so that the allocation is stable over time or under (water) stress. Fairness deals with the acceptability, both ethically and legally, of the water allocation schedule and its characteristics.

The relevance of assessing these characteristics of transboundary river management is evident. There are more than 250 international transboundary rivers and much more when one considers rivers that cross federal state-, provincial- and other sub-national borders. Many of these rivers are located in regions where demand exceeds supply. Existing transboundary allocation regimes, if present, are under pressure due to increasing demand caused by population growth, and developments in industry and agriculture. Simultaneously, in many river basins, water supply is negatively affected by climate change, both in average runoff and in variability of runoff. Widening gaps between demand and supply imply increasing scarcity of water. Increasing scarcity, on its turn, implies that countries are under pressure to increase or at least preserve their share of the available water.

The topic of transboundary river management is studied by many disciplines; most notably hydrology, geography and political science, but there are several good reasons to provide an economic assessment too. One of these is that water can be treated as an economic good albeit with several distinctive features, including (1) its mixture of public- and private good characteristics; (2) its mobility; (3) its variability in space and time; (4) its essentialness in consumption and production; and (5) its heterogeneity in location, timing, quality and uncertainty (Hanemann, 2006). A second reason is that countries have strong economic incentives to obtain a large share of the available water and therefore we are likely to see strategic behavior in water-scarce river basins. The field of economics is exactly concerned with analyzing such strategic choices.

Our focus on the key objectives of efficiency, sustainability and fairness is based on recent developments in the literature on the economics of transboundary river management. This literature emerged in the 1960s with a focus on efficiency of water use, but more recent contributions have brought sustainability and fairness to the research frontier, for reasons that will become apparent in the remainder of this chapter. 
In terms of methodology the focus of this chapter lies with game-theoretic models of water allocation in transboundary river basins. Game theory is a branch of economic theory that analyzes behavior in situations of strategic interaction. It is therefore well-suited to analyze the interaction between riparian countries regarding their decisions on water use. This chapter complements two review papers of the literature. Carraro et al. (2007) reviewed applications of non-cooperative bargaining theory to water allocation, but only very descriptively and without a focus on transboundary settings. More recently and using this transboundary setting, Béal et al. (2013) reviewed the dominant cooperative approach to transboundary river water allocation: the axiomatic approach. In this chapter we combine and extend both reviews in order to cover both non-cooperative as well as cooperative approaches. We do so using a simple economic model of transboundary river water allocation that is usually referred to as the 'river sharing problem'.

\section{From water bodies to rivers}

Before introducing and analyzing the river sharing problem in subsequent sections, we emphasize its limited scope. The river sharing problem, as we present it, makes two important simplifications: (i) it is constrained to linear rivers with (ii) a through-border river geography. This geography implies that rivers cross each border only once and do not create borders. As a result, the riparian countries are located sequentially along the river. These simplifications allow us to avoid complicating factors in the analysis of solutions to the river sharing problem. They exclude, however, many settings that are highly relevant for transboundary river management such as the management of transboundary rivers with other geographies (e.g. border-creator rivers) and rivers with tributaries (cf. Dinar, 2006; 2007).

Going one step further, by focusing on transboundary river basin management, we exclude the management of other transboundary water bodies, most notably shared lakes and shared aquifers. There is a large literature on the management of such water bodies which, by absence of an upstream-downstream setting, is more closely related to standard common-pool problems. Consequentially, the analysis of and solutions to these problems tend to be in line with the literature on common-pool problems (cf. Ostrom, 1990), including studies on efficiency, sustainability and fairness, while accounting for the distinctive features of water as an economic good as introduced in Section 1.

For shared aquifers, an additional complexity is that, unlike rivers, their volume is determined by (past) pumping rates and recharge, while the net benefits of groundwater use depends on the groundwater table. That is, aquifer management is a dynamic problem, while river management can (to some extent) be treated as a static year-by-year problem. As a result, analysis of the 
management of transboundary aquifers is complex. The focus of the economics literature has been to compare management strategies in terms of pumping rates. The optimal management strategy is to maximize the benefits of groundwater use while taking into account its impact on the groundwater table (Gisser and Sanchez, 1980). In a transboundary setting, however, countries may make independent decisions on pumping rates which leads to externalities in terms of pumping costs (one country's pumping decreases all countries' groundwater table) and strategy (pumping more water prevents others from doing so). These externalities have been studied by a.o. Negri (1989), Provencher and Burt (1993), and Rubio and Casino (2003) and a general result is that the level of these externalities is not substantial compared to optimal (i.e. cooperative) management, although this result cannot explain the mixed empirical evidence on success and failure of transboundary aquifer management.

By focusing on rivers, rather than lakes or aquifers, we avoid discussing the large literature on common-pool problems. Instead, because of the explicit upstream-downstream setting of river basins, its analysis is different from many other problems. Our focus on cross-border river geographies and linear rivers is a pragmatic one. It allows us to avoid mathematical complexity. We should note, however, that some of the results presented in the following sections have been generalized to more general river geographies (e.g. rivers with multiple sources and/or multiple sinks). Finally, much of the literature that does not limit itself to cross-border river geographies and linear rivers deals mainly with specific case studies and river basins. Some of these studies are referred to in the following sections, where relevant.

\section{The river sharing problem}

The model that we use to assess the efficiency, sustainability and fairness of transboundary river water allocation is a crude simplification of reality that allows us to analyze transboundary river water allocation with just a few variables and parameters. To focus on the economic aspects of transboundary river management, we leave out many elements that would make the problem more complex. This includes, for instance, hydrological processes such as evaporation, minimum flows, and return flows as well as political factors such as political power and diplomacy. Nevertheless, we do consider most of the distinctive features of water as identified by Hanemann (2006). One exception, however, is that we use aggregate country-wide benefit functions of water use, which ignores the heterogeneity of water. What results is a simple model with three main features that is known as the river sharing problem, at least since Ambec and Sprumont (2002). 


\subsection{Three main model features}

We now present the three main features of the river sharing problem. First, we look at countries that are located along a river. The countries can be ordered from upstream to downstream and we ignore any tributaries or deltas. This order of countries is denoted by the ordered set $N \equiv$ $(1,2, \ldots, n)$ where countries are ordered such that, for each $i, j \in N$, country $i$ is upstream of country $j$ if and only if $i<j$, see Figure 1 .

Second, we aggregate all additions to river flow from tributaries and rainfall into a single parameter for each country that we term endowment. Endowments may or may not be correlated between countries and they may vary between years due to differences in e.g. precipitation. Endowments are denoted by a vector $e=\left(e_{1}, e_{2}, \ldots, e_{n}\right)$, with endowments $e_{i}$ indexed by country $i$. In order to keep the notation simple, we will omit a subscript to denote time.

Third, we consider aggregate country-wide benefit functions of water use. Water is typically used for three main purposes: household use (e.g. tap water), industry (e.g. cooling, production), and agriculture (e.g. irrigation), with the bulk of water generally going to irrigated agriculture. Sectoral demand functions for water can be combined to obtain the aggregate benefit functions which we denote by $b_{i}\left(x_{i}\right)$ where $x_{i}$ denotes water use by country $i$. We assume that benefit functions denote the benefits of water use net of abstraction costs and we write $b=$ $\left(b_{1}\left(x_{1}\right), b_{2}\left(x_{2}\right), \ldots, b_{n}\left(x_{n}\right)\right)$. The properties of $b_{i}\left(x_{i}\right)$ may vary, but generally we assume that $b_{i}\left(x_{i}\right)$ is concave and increasing in $x_{i}$. Also, $b_{i}\left(x_{i}\right)$ is differentiable for all $x_{i} \geq 0$. Sometimes it is required that its derivative $b_{i}^{\prime}\left(x_{i}\right)$ goes to infinity as $x_{i}$ tends to 0 . This limit behavior implies that efficiency of water can always be improved by reallocating a small amount of water to any country that could not abstract water under its existing allocation. Finally, denote by $\hat{x}_{i}$ the satiation point of water use for country $i$ such that, if a satiation point exists, we have $b_{i}^{\prime}\left(\hat{x}_{i}\right)=0$. Examples of benefit functions are displayed in Figure 2.

An important observation is that in most countries, typically about $60-80 \%$ of water is used for agriculture, the vast majority of which for irrigation purposes, at lower marginal benefits than water used for households, industry, and some high-value agricultural uses. This observation implies that a large part of the domain of $b_{i}\left(x_{i}\right)$, and typically the tail of this function, will be (approximately) linear in water use. In the tail of the benefit function, marginal benefits of water use are relatively low and more or less constant, since an increase in water use would imply an increase in the area of irrigated agriculture with marginal benefits more or less equal to existing irrigated agriculture. This observation is backed up by inspection of models that assess possibilities for cooperation in transboundary basins. These typically assume equal marginal benefits (e.g. Whittington et al., 2005) or they show negligible or small differences in marginal 
benefits between countries, e.g. <1\% in models of the Nile and Syr Darya basin (Whittington et al., 2005; Ambec et al., 2013) and 12\% in a model of the Mekong basin (Houba et al., 2013). Realistic benefit functions (see Figure 2) would therefore be increasing steeply, reflecting high-value uses in households and industry, followed by a long linear tail with low and constant marginal benefits.

Based on the three main features outlined here, a river sharing problem can now be denoted by the triple $\langle N, e, b\rangle$. In the remainder of this chapter we are interested in various possible solutions to this problem.

\subsection{Adding a scarcity constraint}

Before turning to the solution of the river sharing problem, note that the interesting case to analyze is when water is scarce, which requires that we put a scarcity constraint on the model. When benefit functions have no satiation points $\hat{x}_{i} \leq \sum_{j \leq i} e_{j}$ on the relevant domain, water can always be put to beneficial use so that scarcity is guaranteed. When benefit functions do have satiation points, Ambec and Ehlers ( 2008b, Remark 2) have shown that, without loss of generality, we can make the following assumption.

Assumption 1 Each country's satiation point is weakly larger than its endowment: $\hat{x}_{i} \geq e_{i} \forall i \in$ $N$.

Since river flow is unidirectional and upstream transportation of water is usually prohibitively costly, we assume that water can only be used in the country where it originates or in downstream countries. Denote by $E_{i}$ the available water on the territory of country $i$, such that

$$
E_{i}=e_{i}+\sum_{j<i}\left(e_{j}-x_{j}\right)
$$

$E_{1}=e_{1}$ is given and values for $E_{2}, E_{3}, \ldots, E_{n}$ can be calculated recursively when following the order of agents down the river.

Water use cannot exceed availability:

$$
x_{i} \leq E_{i} \forall i \in N
$$

but some amount $u_{i} \geq 0$ of available water may be left in the river and so is unused:

$$
u_{i} \equiv E_{i}-x_{i}
$$

As a result, available water $E_{i} \equiv e_{i}+u_{i-1}$ can also be represented as the sum of endowments and unused upstream water as can be seen in Figure 1.This interpretation allows to calculate available water recursively, starting upstream at agent 1 and moving down the river, by adding endowments and subtracting water use at each location. Figure 1 illustrates the model for $n=4$. 
Because of scarcity as introduced by Assumption 3.2, any efficient solution to the river sharing problem in this example will have $u_{4}=0$. Obviously this observation generalizes to any river sharing problem in which efficient solutions imply that $u_{n}=0$ (obviously this ignores the benefits of e.g. environmental flows).

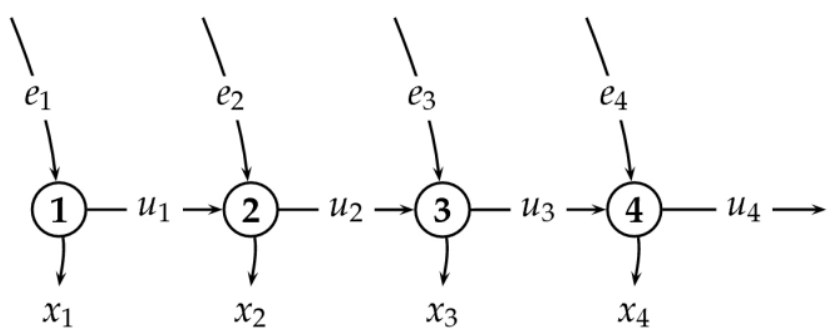

Figure 1: The river sharing problem for $n=4$; nodes are countries and arrows indicate water flows: endowments $e_{i}$, unused water $u_{i}$, and water use $x_{i}$.

\subsection{Solutions to the river sharing problem}

A solution to the river sharing problem consists of two vectors: a water allocation vector $x=$ $\left(x_{1}, x_{2}, \ldots, x_{n}\right)$ and a vector of monetary transfers $\mathrm{t}=\left(t_{1}, t_{2}, \ldots, t_{n}\right)$, where $t_{i}>0$ indicates that the country receives a net monetary transfer and vice versa. We assume that transfers are not bounded by a budget constraint and that payments are contingent upon the realization of the water allocation vector. Solutions can be implemented in several ways. One of these is the formalization of the solution in a water allocation agreement or treaty (Beach et al., 2000). Since the beginning of the twentieth century, more than 145 agreements on water use in transboundary rivers were signed. Almost half of these cover water allocation issues (Wolf, 1998). Alternatively, the solution to a river sharing problem can be arranged informally, possibly backed up by a joint river basin committee (Dombrowsky, 2007) or implemented in the form of transboundary water trade (cf. Wang, 2011).

We should note here that part of the literature on transboundary river management is skeptical about the use of monetary transfers between sovereign states. Monetary payments may be politically impossible or may not be applicable because it is not straightforward to quantify and monetize the benefits from water use. Indeed, there is only limited evidence of actual payments in exchange for water deliveries (Dinar et al., 1992; Dinar, 2006). For instance, the International Freshwater Treaties Database Wolf (1998) contains only nine (out of 49) water allocation agreements in which payments are linked explicitly to the allocation of water. An alternative interpretation of transfers, however, is that they represent in-kind transfers. In-kind transfers refer to linking water transfers to some other issue of negotiation between the two countries in which the structure of benefit sharing is reversed (Bennett et al., 1998). For example, the Netherlands 
linked the issue of water allocation in the Meuse river to the issue of navigation on the Scheldt river. By linking these two issues, The Netherlands would gain from the water allocation treaty, while Belgium would gain from improved navigation options to the Antwerp harbor. Eventually, though, it was opted to link the agreement on water allocation to the routing of an international railway track (Mostert, 2003).

In case where both monetary and in-kind transfers do not apply, the solution to a river sharing problem consists of the water allocation vector $x$ only, while the transfer vector is set to zero: $t=(0, \ldots, 0)$. Note that our solution concept is very broad. It includes both cooperative and non-cooperative approaches to solve the river sharing problem. It also includes, however, conflicts over river water as these might lead to a stalemate setting where countries refuse to share river water and/or refuse to make monetary payments in return.

Given $x$ and $t$, countries' utilities can now be written as follows:

$$
\pi_{i}\left(x_{i}, t_{i}\right)=b_{i}\left(x_{i}\right)+t_{i}
$$

This general utility function features quasi-linear preferences over money and water, implying some form of substitutability between the two in utility terms. This utility function is convenient because, by Houba et al. (2014), we know that it allows solving the water allocation vector separately from the vector of monetary transfers. That is, given some (cooperative or non-cooperative) procedure to solve the river sharing problem, the additivity of (4) allows to first solve the problem to obtain $x$ and subsequently determine or negotiate an appropriate $t$.

Given the utility function in (4), and given water availability as defined in (1), a (narrow) definition of the objective of transboundary river management is to find vectors $x$ and $t$ that solve the following maximization problem:

$$
\begin{aligned}
& \operatorname{Max}_{x, t} \sum_{i \in N} \pi_{i}\left(x_{i}, t_{i}\right) \quad \text { s.t. } \\
& 0 \leq x_{i} \leq E_{i} \quad \forall i \in N \\
& \sum_{i \in N} t_{i}=0
\end{aligned}
$$

As discussed a.o. in the next section, there may be additional constraints on this maximization problem, which will subsequently restrict the maximal total benefits from water use in the river. These constraints may come from the setting of the river sharing problem (see Section 3.4), but also from two of the three key objectives of transboundary river management: sustainability and fairness (the third objective, efficiency, is implied by the maximization problem and therefore cannot constrain its maximum). 


\subsection{Property rights in the river}

The main motivation for the presence of monetary transfers in the solution to a river sharing problem is the possible presence of (perceived) property rights to river water. As noted by Hanemann (2006), the structure of property rights to water is different due to its distinctive features. Clearly, there is a strategic incentive for countries to claim that they hold property rights over water.

Note that there is no supra-national authority (Barrett, 1994) to enforce any property rights in the river, so these rights need to be credible on their own. There are several arguments that are generally employed to lend credibility to claims of property rights. One is to resort to principles from international water law, such as the 1966 Helsinki Rules or the 1997 UN Watercourses Convention. Two main principles stand out: "reasonable and equitable utilization" and "no significant harm to other riparians", giving (weak and ambiguous) priority to, respectively, upstream and downstream countries. A second argument is to resort to more extreme principles such as Absolute Territorial Sovereignty (ATS, also referred to as the Harmon Doctrine), which says that every country has the right to all river water within its territory, or Unlimited Territorial Integrity (UTI), which says that every country has the right to all river water within and upstream of its territory (Salman, 2007).

In absence of well-defined property rights, it may be hard for countries to agree on implementing a more efficient allocation by trade or agreement, since such a move would implicitly assign such property rights (Holden and Thobani, 1996; Ansink and Weikard, 2009). The status quo allocation is therefore a natural starting point to implement any solution to the river sharing problem. We will assume that this status quo corresponds to the ATS principle, where each country controls the water on its territory, while stressing that the status quo does not necessarily correspond to actual property rights, acknowledged by all countries in the river basin. Moes (2013) supports this status quo by arguing that the ATS principle can be interpreted as a

"default position that (upstream) states can take prior to negotiations of international water agreements".

Note that alternative implementations of the status quo can be easily implemented by a suitable adjustment of the endowments vector $e$. For instance, if the status quo is such that a large share of country $i$ 's upstream water endowment $e_{i}$ is controlled by a downstream country $k>i$ (cf. the Nile basin), one can adjust the endowment vector from $e$ to $e^{\prime}=\left(e^{\prime}{ }_{1}, e^{\prime}{ }_{2}, \ldots, e^{\prime}{ }_{n}\right)$ such that $e_{i}^{\prime}=e_{i}-\gamma, e_{k}^{\prime}=e_{k}+\gamma$, and $e_{j}^{\prime}=e_{j} \forall j \in N \backslash\{i, k\}$, where $\gamma: 0<\gamma \leq e_{i}$ represents the adjustment. 


\subsection{The river claims problem as a special case}

A special case of the river sharing problem was observed by Van den Brink et al. (2014). This case features linear benefit functions up to a satiation point, as shown in Figure 2. That is, every country has constant marginal benefits equal to one up to a satiation point, and marginal benefits equal to zero thereafter. This case is the so-called river claims problem, in which each country's satiation point is interpreted as its 'claim'. A second interpretation of these claims is that they are based on some principle for river sharing (Wolf, 1999; Wirsing and Jasparro, 2007; Daoudy, 2008). The list of possible principles is large and includes principles from international water law, or perceived rights based on historical use, the amount of irrigated land, population size, etc.

Irrespective of the interpretation of claims, employing a river claims problem may be preferred over a river sharing problem if the countries' benefit functions are unknown or considered irrelevant for the river sharing problem. Specifically, in a river claims problem, a vector of claims replaces the vector of benefit functions as the basis of countries' appreciation of water use. As a result, river claims problems have nothing to say about the efficiency of water use. We make a small modification in notation in order to distinguish the river claims problem from the river sharing problem. Specifically, claims are denoted by a vector $\mathrm{c}=\left(c_{1}, c_{2}, \ldots, c_{n}\right)$, with claims $c_{i}$ indexed by country $i$. Based on the claims vector, a river claims problem can now be denoted by the triple $\langle N, e, c\rangle$.

Since the river claims problem can be considered a special case of the river sharing problem, its solution in terms of vectors $x$ and $t$ can be obtained in a similar way. Nevertheless, we will see later in this chapter that existing solutions to the river claims problem typically do not require transfers so that $t=(0, \ldots, 0)$.

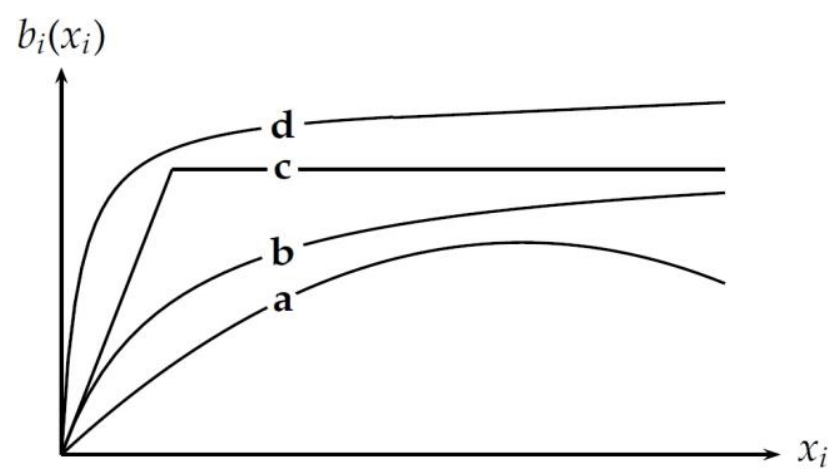

Figure 2: Four possible shapes of the benefit function $b_{i}\left(x_{i}\right)$ : (a) satiated; (b) non-satiated; (c) the 'claims' function with linear benefits up to a satiation point; and (d) the realistic function with first a steep increase and subsequently low constant marginal benefits. 


\section{Efficiency}

The appropriate concept of efficiency to assess solutions to the river sharing problem is Kaldor-Hicks efficiency of the water allocation vector $x$. This measure of efficiency ignores the distribution of the benefits of water use over the countries, assuming that any undesirable distribution can be corrected via adjustments to the monetary transfer vector $t$. As a result, Kaldor-Hicks efficiency is obtained when the total benefits of water use in the river basin are maximized, in line with the maximization problem presented in Section 3.3.

Standard economic theory prescribes that efficient solutions feature equal marginal benefits of water use $b^{\prime}{ }_{i}\left(x_{i}\right)$ among the countries in the river basin. In the river sharing problem, this may be impossible. The reason lies in the unidirectional flow of water. The availability constraint (2) implies that downstream water cannot be transferred upstream. As a result, we may have $b^{\prime}{ }_{i}\left(x_{i}\right)>b^{\prime}{ }_{i+1}\left(x_{i+1}\right)$ with $x_{i}=E_{i}$ and no option to increase $E_{i}$. Therefore, the vector of marginal benefits $\left(b^{\prime}{ }_{1}\left(x_{1}\right), b^{\prime}{ }_{2}\left(x_{2}\right), \ldots, b_{n}^{\prime}\left(x_{n}\right)\right)$ is such that in the efficient solution, marginal benefits decrease (weakly) as we move downstream along the river (Kilgour and Dinar, 2001). Jumps in marginal benefits from one country to the next correspond to locations where upstream water is 'scarcer' than downstream water.

Monetary transfers may be required to accommodate the efficient water allocation vector. This is straightforward in case of generally acknowledged property rights to river water. In absence of such rights, the status quo allocation gives each country control of its own endowment of water. Before implementation of the efficient allocation, upstream countries had the opportunity to abstract more than their share in the efficient allocation $x^{*}$ and therefore they may be compensated for reducing their water use. Formally, denote the status quo allocation vector by $x^{0}$ and the (Kaldor-Hicks) efficient allocation vector by $x^{*}$. Assume that the vectors are not equal so that for at least one country $i$ we have $x_{i}^{*}<x_{i}^{0}$. Without loss of generality, assume that this decrease in water use holds for exactly one country. The minimal compensation $t_{i}^{m}$ to this country (where superscript $m$ refers to minimal) equals $t_{i}^{m}=b_{i}\left(x_{i}^{*}\right)-b_{i}\left(x_{i}^{0}\right)$. Given that $x^{*}$ is Kaldor-Hicks efficient, we know that there is a positive surplus by implementing the efficient allocation vector, equal to $\sum_{j>i}\left[b_{j}\left(x_{j}^{*}\right)-b_{j}\left(x_{j}^{0}\right)\right]-t_{i}^{m}>0$. Given this strict inequality, countries downstream of $i$ can jointly transfer $t_{i}^{m}$ to country $i$ and still gain from the implementation.

Some solutions to the river sharing problem will require that transfers exceed the minimal compensation, for instance to make the solution sustainable or because this is considered fair. In this case, the surplus from the efficient allocation is shared according to some sharing rule, depending on the characteristics of the solution. 


\subsection{Implementation of the efficient water allocation vector}

Clearly, the efficient water allocation vector $x^{*}$ is desirable and a key objective of any procedure to share river water. The implementation of $x^{*}$, however, can be achieved in multiple ways and we highlight three approaches. Each of these may be applicable in different settings, depending on the characteristics and preferences of the river basin countries.

\section{Transboundary water trade}

When water is scarce and when property rights are well defined, a difference in the marginal value of water between two countries - greater than the costs of transferring the water-is expected to lead to (bilateral) trade in water (Rosegrant and Binswanger, 1994; Holden and Thobani, 1996; Ansink and Houba, 2012). Water trade, or water marketing is fairly common within national boundaries (cf. Bjornlund and McKay, 2002; Chong and Sunding, 2006), where trade occurs between individual users of water, usually farmers. Nevertheless there are also examples of water trade across boundaries: river basin boundaries, provincial/state boundaries (e.g. Australia, U.S.), and national boundaries (e.g. selected examples in e.g. Wolf (1998), Beach et al. (2000) and Dinar (2006) should be interpreted as water trade rather than agreements).

Given the unidirectional flow of rivers, water trade involves the passing of water by the selling (upstream) country to the purchasing (downstream) country, in exchange for an agreed upon compensation. Water trade between non-adjacent countries is troublesome since, in absence of property rights to river water, any intermediate country could seize the additional inflow on its territory, thereby obstructing the trade (Bhaduri and Barbier, 2008). Therefore, we consider bilateral trade only. Lekakis (1998) demonstrated for $n=2$ that such trade, obviously, implements the efficient water allocation vector $x^{*}$. Extending this result to $n$ countries, Wang (2011) demonstrated that a sequence of bilateral trades in a river with any number of countries converges the water allocation vector to $x^{*}$. This last result, however, hinges on a specific assumption on the price of water that is agreed upon. Specifically, the authors assume that this price equals the marginal benefit of water use of the two countries at their equilibrium allocation. Without this assumption, reaching $x^{*}$ is unlikely.

Yet, this assumption is not very strong, which can be seen from the analogy of water prices with equilibrium prices in a Walrasian equilibrium made by Houba (2008). Based on the second welfare theorem, we know that efficient allocations can be regarded as Walrasian equilibria, in which prices coincide with the shadow price of water, that is, the marginal benefits of water use given $x^{*}$. As a result, these prices coincide with the assumed prices by Wang (2011). In addition, the shadow price of water is also a focal price as it is the only price at which all options for profitable trade are exhausted. 


\section{Water allocation agreements}

When water is scarce, countries may opt to negotiate a basin-wide agreement on the allocation of water (cf. Wang et al., 2008), rather than engage in bilateral water trade. There are two main reasons for doing so. The first reason is that one or more countries may be unhappy with the status quo allocation of water since they consider it unfair or undesirable. A second reason is that countries may worry about the future impacts to the status quo allocation by e.g. increasing demand or impacts of climate change on water supply. By formalizing the current allocation in an agreement, they implicitly recognize each country's property rights to water in the basin.

Note that most existing agreements are not basin-wide agreements. For example, whereas only $66 \%$ of international river basins are shared by two countries, more than $85 \%$ of agreements listed in the International Freshwater Treaties Database (IFTD, see www.transboundarywaters.orst.edu) are bilateral. Also, monetary transfers are usually absent from such agreements. In fact, as was already mentioned in Section 3.3, the IFTD contains only nine water allocation agreements where payments are explicitly linked to the allocation of water. Details of these agreements are given in Table 1. Note that other agreements may either use in-kind transfers or no transfers at all. This last option is a natural choice in case the agreement only formalizes the status quo allocation.

Table 1: Agreements on water allocation with payment details.

\section{Basin (year) and agreement name}

Indus (1892): Amended terms of agreement between the British Government and the State of Jind, for regulating the supply of water for irrigation from the Western Jumana Canal.

Gulf of Aden drainage basin (1910): Convention regarding the water supply of Aden between Great Britain and the Sultan of Abdali.

Gash (1925): Exchange of notes between the United Kingdom and Italy respecting the regulation of the utilization of the waters of the River Gash.

Näätämo (1951): Agreement between the Government of Finland and Norway on the transfer from the course of the Näätämo river to the course of the Gandvik river.

Isonzo (1957): Agreement between the government of the Italian Republic and the

\section{Side payment details}

Jind (India) made a fixed annual payment to

Great Britain for the delivery of water for the irrigation of 50,000 acres through newly constructed distribution works.

Great Britain agreed to make monthly payments to the Sultan of Lahej for extracting groundwater.

Sudan (the United Kingdom) agreed to pay a share of its income from irrigated agriculture to Eritrea (Italy) for passing through the necessary water.

Norway receives water from the Näätämo basin to be used for power generation and compensates Finland for lost water power through a lump-sum payment of NKR 15,000.

Italy pays 58 million lira annually to Yugoslavia for receiving 4.5 million 
government of the Federal People's Republic of MCM/year, which equals $85 \%$ of the total Yugoslavia concerning the water supply of the river flow in the Isonzo. town of Gorizia.

Colorado (1966): Exchange of notes constituting Mexico reimburses losses in power generation an agreement concerning the loan of waters of the to the USA for releasing $50 \mathrm{MCM}$ in the fall of Colorado river for irrigation of lands in the 1966 for irrigation purposes (on top of its Mexicali valley. allocation according to the 1944 Water Treaty).

Roya (1967): Franco-Italian convention France made a one-time ITL 10 million concerning the supply of water to the Commune of Menton.

payment for diverting water from the Roya to supply the village of Menton, while agreeing to pass through a fixed share of its diversion to the Italian village of Ventimiglia.

Helmand (1973): Helmand River Water Treaty. On top of its original allocation of 22 cubic meters per second, Iran was to purchase an additional four cubic meters per second from Afghanistan.

Orange (1986): Treaty on the Lesotho Highlands South Africa agreed to make annual payments Water Project between the Government of the to Lesotho for water transfers, increasing from Republic of South Africa and the Government of EUR 14 million in 1998, when water the Kingdom of Lesotho. deliveries started, to EUR 24 million in 2004.

Reproduced from Ansink and Weikard (2009, Table 1). Sources: Wolf (1999); Beach et al. (2000); Dinar (2006) and the IFTD. Note: The table lists only those agreements where payments are explicitly coupled to water delivery. Therefore, agreements such as the 1926 Cunene Agreement and the 1960 Indus Waters Treaty are not included.

An alternative perspective on a basin-wide agreement is that of the grand coalition. The term coalition refers to partial cooperation within the basin and part of the economics literature on transboundary river management looks exactly at the equilibrium size of coalitions in a river basin (Ambec and Ehlers, 2008b; Ansink et al., 2012). The grand coalition occurs when, in equilibrium, all countries are part of the coalition and this situation allows to implement $x^{*}$ combined with some transfer vector $t$.

\section{Bargaining}

Models that assess bargaining solutions to the river sharing problem usually have the combination of $x$ and $t$ as the subject of bargaining. Although the procedure can be quite different, a bargaining solution on river water can be interpreted either as a water trade outcome or as a water allocation agreement. Trade outcomes can be viewed as bargaining solutions by interpreting the 
resulting water price as the outcome of a bilateral bargaining process (assuming that both aim to implement the efficient water allocation vector). Agreement outcomes can be viewed as bargaining solutions when bargaining involves round-table negotiations with all countries in the basin.

There is only a small number of studies that explicitly model the bargaining process on water allocation, Adams et al. (1996) being one of the first. Other papers that take a bargaining perspective are Houba (2008) and Houba et al. (2014).

The key message of these papers, and of the bargaining approach in general, is that bargaining models will generally implement the efficient water allocation vector $x^{*}$, since this maximizes the 'size of the pie' to bargain about. What sets the bargaining approach apart is that the corresponding transfer vector $t$ depends on the bargaining power of each country. Higher bargaining power is associated with obtaining a large share of the pie and this is generally reflected by receiving a (relatively) large monetary transfer.

\subsection{Why allocations may not be efficient}

Our focus so far on efficient vectors of water allocation may not be very realistic. The literature on transboundary river management has pointed to various reasons why water allocation may (or should) not be efficient at all. Partly this is due to factors that are exogenous to the simple setup of the river sharing problem, and partly this is due to deliberate choices by countries. We will assess five factors that may impede efficiency. One could argue that these same five factors also impede the other two key objectives of transboundary river management: sustainability (Section 5) and fairness (Section 6). We argue, however, that the five factors identified below-and especially the first three factors-will always have a negative impact on effiency, while their effect on sustainability and fairness may be ambiguous.

\section{Political power}

In absence of monetary or in-kind transfers - a situation that we have seen is quite common - the only object of (non-)cooperation is the allocation of river water. In such a setting, the river sharing problem simplifies to a zero-sum game in terms of physical water units. That is, water can be allocated to one country or another, but without compensating transfers, the gains of (re-)allocating each unit of water can go to only one country. In other words, there is no surplus from implementing the efficient allocation vector $x^{*}$ and one party will lose from doing so. As a result, there is also no incentive for countries to coordinate on $x^{*}$, be it via trade, bargaining, or an agreement. 
In absence of this incentive to seek efficiency, the allocation of water is likely to be determined by mere political (or military) power. The impact and outcome of such power interactions in a river basin is beyond the scope of this chapter, but is studied in depth in a series of papers in the domains of political sciences and international relations, for instance using the framework of ‘hydro-hegemony' (Zeitoun and Warner, 2006).

\section{Water security}

As discussed in the introduction, water is essential in both consumption and production (Hanemann, 2006). As a result, countries have a strong incentive to safeguard at least their status quo allocation. This provides them with a reliable availability of water to satisfy essential needs, including energy and food security. Transferring water to other countries in return for compensation - through water trade, bargaining, or an agreement - may be beneficial in the short term, but there is obviously a risk that conditions may change over time such that the water transfer becomes undesirable. One option is that demand for water increases due to population growth or that supply decreases due to impacts of climatic change on the hydrological cycle. This risk of an undesirable water transfer is especially pronounced when water allocations are perceived as property rights to river water. If so, then consequentially a transfer of water is considered a transfer of property rights, either formally or informally. Countries may fear, rightfully or not, that transferring their water may have permanent consequences, which would thereby affect their water security. Lekakis (1998) phrases this fear as follows, based on Gleick (1994):

\footnotetext{
"It appears that the main reason behind the absence of effective international water resource allocation schemes is the fear of those countries, which access the water flow first, that a future water shortage might limit their political and economic options".
}

\section{Water as a contentious good}

In addition to concerns over water security, and in addition to the distinctive features of water, there is another element that sets water apart as a special good. This element is that water is a contentious good in the sense that any reduction in water availability is likely to cause argument or controversy. This element may be inspired by cultural, traditional, religious, or historical perceptions of water. These perceptions lead to additional non-use values of water that are not captured in the aggregated benefit functions $b_{i}\left(x_{i}\right)$. 
To illustrate, consider the following quote of the former president Morsi of Egypt in June 2013 with respect to the possible effects on Nile river flow of a new dam under construction in upstream Ethiopia:

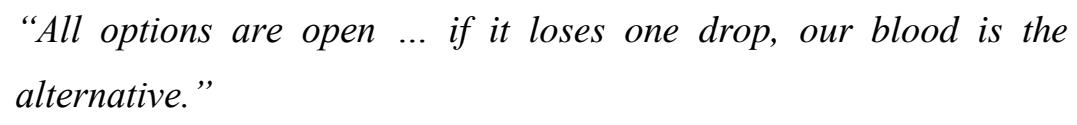

This quote illustrates that any reduction in river flow will cause great controversy at minimum. The status quo water allocation is clearly to be defended with all means possible. As a result, the contentious nature of water may obstruct efficiency-improving reallocations of water, since governments cannot simply treat water as any other conventional commodity.

Besides non-use values driven by various perceptions of water, one additional driving force for the contentious nature of water is that in many countries water is essential for livelihoods of a large share of the population. Continuing upon the Nile example, a large agricultural population relies on annual available river flow to irrigate their crops. Reductions in water availability have direct and profound effects on livelihoods. Governments are reluctant to make any decisions on river flow allocations that would reduce water available and thereby affect livelihoods, if only for electoral reasons and public support.

\section{Transaction costs}

The Coase theorem applied to water resources implies that the efficient use of river water does not depend on the distribution of property rights to water. Transaction costs, arising from a.o. information gathering, negotiations, monitoring and enforcement, can obviously obstruct efficiency improvements (Richards and Singh, 2001). In the relatively simple setting of regional water markets, where buyers and sellers are in one country subject to national laws, transaction costs have already been identified as an important source of friction (Carey et al., 2002; Chong and Sunding, 2006). It is not hard to imagine that this friction is even worse in a transboundary setting, without a supranational authority for monitoring and enforcement, without a common methodology for information gathering, and without standard procedures to determine quantities and prices.

The presence of well-functioning institutions may assist in reducing the transaction costs of negotiations (Dombrowsky, 2007). Such institutions are in place in many river basins, for instance in the form of so-called joint river basin committees. Nevertheless, not all of these committees function equally well due to capacity or legal constraints, or due to cultural or political frictions between the countries involved. In addition, they are unlikely to render transaction costs negligible. 
Given non-zero transaction costs, reallocation of water is only beneficial when the difference in marginal benefits outweighs the transaction cost. In light of the negligible or small differences in marginal benefits between countries discussed in Section 3.1, it is questionable whether reallocation in such basins would exceed transaction costs, even if the latter are relatively low.

\section{Simple sharing rules}

Existing sharing rules for river water allocation may not necessarily be efficient. When sharing rules exist, they are usually formalized in a water allocation agreement. For instance, the Nile Waters Agreement (Egypt, Sudan) allocates 48,000 MCM/yr to Egypt and 4,000 MCM/year to Sudan, based on what was perceived at the time as acquired rights. Of any remaining flow, $34 \%$ is allocated to Egypt and 66\% to Sudan (NWA, 1959). This sharing rule cannot be efficient since it does not assign any water to upstream countries in the basin.

Most sharing rules are simple sharing rules in the sense that they use simple rules of thumb to allocate river water. The two most common examples are proportional and fixed amount sharing rules (Dinar et al., 1997; Wolf, 1998). An example of a proportional sharing rule is the 1975 Euphrates Agreement (Iran, Iraq) in which the flows of the Bnava Suta, Qurahtu, and Gangir rivers were divided equally (Beach et al., 2000). An example of a fixed amount sharing rule is the 1959 Agreement between Nepal and India on the Gandak irrigation and power project, in which irrigation water was allocated for 40,000 acres in Nepal and 103,500 acres in India (Beach et al., 2000).

It may well be that these agreed-upon allocations are efficient in a year with average river flow. When a given year, however, due to the natural variability of river flow, is particularly wet (or dry), then simple sharing rules are unlikely to lead to efficient allocations (Bennett et al., 2000). Kilgour and Dinar $(1995,2001)$ recognized this possible efficiency loss and introduced the notion of flexible river sharing. That is, agreements on river water allocation can make the water allocation vector $x$ and the monetary transfer vector $t$ contingent on realized river flow. Such a flexible agreement would choose $x^{*}$ contingent on the vector of endowments $e$ (recall we omit subscripts for time), and determine the appropriate vector of transfers $t$ (similar to Houba (2008) and Wang (2011) discussed in Section 4.1, Kilgour and Dinar (2001) use water prices equal to the shadow price of water).

\subsection{Efficiency in the river claims problem}

In the special case of the river claims problem introduced in Section 3.5 we find that efficiency depends on the interpretation of the problem. We discussed two interpretations. First, if claims are based on linear benefit functions (i.e. constant marginal benefits equal to one, up to a satiation 
point), any allocation of water equates marginal benefits across all countries in the basin. As a result, all allocations are efficient. Second, if claims are based on some principle for river sharing as discussed in Section 3.5, the river claims problem ignores the benefit functions and therefore inefficient allocations are possible (but this occurs outside the model and is therefore considered irrelevant).

\section{Sustainability}

Next to efficiency, a second key objective of transboundary river management is sustainability. In the context of the river sharing problem, we argue that sustainability builds upon efficiency in the sense that sustainability assesses the stability (or resilience) of the efficient water allocation vector. We will focus on just one threat to the sustainability of water allocation. This threat is the variability of river flow, and connected to this, the uncertainty of river flow in the next periods. In the setting of water-scarce river basins, when river flow is above average, countries will generally have no incentive to deviate from the agreed allocation. When river flow is below average, however, countries may have an incentive to deviate, thereby breaking the sustainability of the allocation (Ward, 2013).

There are many examples of unsustainable allocations due to, mainly, low river flow. We mention five:

1. Mexico failed to meet its required average water deliveries under the 1944 US-Mexico Water Treaty in the years 1992-1997 (Gastélum et al., 2009).

2. Israel announced during the $1998-2000$ drought in the Jordan basin that it was not able to allow Jordan its allotted share under their water agreement (Ambec et al., 2013).

3. India extended its trial operation of the newly constructed Farakka barrage in the Ganges basin throughout the 1975-1976 dry season, diverting water away from the Ganges and through the new canal at full capacity, causing severe water shortages in Bangladesh (Beach et al., 2000).

4. India diverted all water supply away from Pakistan's irrigation canals in 1948 during a dispute on water rights related to the partitioning of the Indian subcontinent (Barrett, 1994).

5. Turkey diverted all the water from the Euphrates for a month to create a reservoir behind the newly constructed Atatürk Dam in 1990, depriving downstream Syria and Iraq of water. 


\subsection{Hydrological characteristics}

Three hydrological characteristics of river flow create the incentives to defect from agreed-upon allocations. First, river flow is not a constant but a stochastic process, typically displaying both inter-annual and seasonal variability as well as daily variation (Dettinger and Diaz, 2000; Ward et al., 2010). The variability of river flow depends on many factors, including the climatological and morphological conditions of the river basin. For example, a snow-dominated river basin will have a different monthly distribution of river flow than a rain-fed river basin. As a result, the decision to apply a sharing rule for water allocation to the volume of annual river flow is ad hoc and may bias the outcome (e.g. when such annual sharing gives a different outcome than the sum of allocations of monthly sharing).

Second, despite technological developments in forecasting methods, river flow is characterized by uncertainty (Krzysztofowicz, 2001; Montanari and Grossi, 2008). An agreed allocation at the start of the year may become obsolete, impossible or undesirable if the realized volume of river flow deviates from the expected volume. Given hydrological uncertainty, such deviations are hard to avoid.

Third, in addition to increases in flow variability and the frequency of extreme events, climate change induces changes in mean river flow for many river basins (Milly et al., 2005; Bates et al., 2008). Such permanent changes in water availability call for permanent changes in the allocation vector, or an allocation vector that is contingent on river flow.

Only a minority of current transboundary agreements take into account these hydrological characteristics of river flow (De Stefano et al., 2012). Most agreements do not; they either allocate fixed or proportional shares, or they are ambiguous in their schedule for water allocation. Clearly, this has implications for both their efficiency and their sustainability.

\subsection{Sustainable solutions to the river sharing problem}

Given the hydrological characteristics of river flow and the anecdotal evidence on unsustainable allocations presented above, we now proceed to assess the sustainability of solutions to the river sharing problem. We start with some results for $n=2$ and simple sharing rules, as discussed in Section 4.2 and subsequently proceed to more general results. An important observation to make here is that the flexible sharing rules introduced by Kilgour and Dinar (2001) are not necessarily sustainable. The reason is that, despite these rules being contingent on realized river flow (and efficient), the vector of transfers is based on the shadow price of water in a static framework, which ignores strategic incentives to deviate from the agreement. As we will see below, in a dynamic setting, monetary transfers are not necessarily equal to this shadow price. 
Consider a river sharing problem with $n=2$ and $e=\left(e_{1}, 0\right)$. Each year's realization of the upstream endowment is taken from some probability distribution $f\left(e_{1}\right)$. Since downstream water cannot be shared, the downstream country's endowment $e_{2}$ is normalized to 0 in order to focus on the sharing of upstream water only. Consider the following simple sharing rules, in which $E()$ denotes the expectation operator:

Proportional allocation (PA): Country 1 is allocated $\alpha e_{1}$ and country 2 is allocated $(1-\alpha) e_{1}$, with $0<\alpha<1$

Fixed upstream allocation (FU): Country 1 is allocated $\min \left\{\beta, e_{1}\right\}$ and country 2 is allocated $\max \left\{\mathrm{e}_{1}-\beta, 0\right\}$, with $0<\beta<E\left(e_{1}\right)$;

Fixed downstream allocation (FD): Country 1 is allocated $\max \left\{e_{1}-\gamma, 0\right\}$ and country 2 is allocated $\min \left\{e_{1}, \gamma\right\}$, with $0<\gamma<E\left(e_{1}\right)$.

In addition, consider the following monetary transfer vectors, where superscript $c$ denotes cooperation according to any of the three simple sharing rules, and recall that $t_{i}^{m}$ denotes the minimal compensation to compensate the upstream country for passing water:

Constant: $t_{1}=-t_{2}=E\left[t_{1}^{m}\right]+E\left[\epsilon\left(b_{1}\left(x_{1}^{c}\right)+b_{2}\left(x_{2}^{c}\right)\right)-\left(b_{1}\left(x_{1}^{0}\right)+b_{2}\left(x_{2}^{0}\right)\right)\right]$;

Flexible: $t_{1}=-t_{2}=t_{1}^{m}+\epsilon\left(b_{1}\left(x_{1}^{c}\right)+b_{2}\left(x_{2}^{c}\right)\right)-\left(b_{1}\left(x_{1}^{0}\right)+b_{2}\left(x_{2}^{0}\right)\right)$.

The constant transfer vector is based on the expected benefits of river flow, minimally compensating country 1 plus a share $\varepsilon$ of the expected surplus. The flexible transfer vector is based on the actual realized benefits of river flow.

Ansink and Ruijs (2008) combine these three water allocation vectors and the two transfer vectors in an infinitely-repeated sequential game The order of events in any stage game is as follows:

1. River flow $e$ is realized;

2. Country 1 chooses $x_{1}$ according to the allocation vector, or defects;

3. Country 2 observes $x_{1}$ and chooses $t_{2}$ according to the transfer vector, or defects;

4. Benefits are realized.

Upon defection, a punishment strategy is employed.

This game gives the following main results:

Result 1 Sustainability of a water allocation agreement depends on the probability density function of river flow. Sustainability decreases if mean river flow decreases. An increased variance can have a positive or a negative effect on sustainability. 
Result 2 Sustainability of a water allocation agreement depends on the water allocation vector. It is higher for fixed upstream allocation than for proportional allocation and lowest for fixed downstream allocation.

Figures 3 and 4 illustrate these results by plotting the incentive to defect for each country and for the relevant transfer vector. It turns out that country 1 only has an incentive to defect with constant transfers and country 2 only with flexible transfers (benefit functions used in this illustrations are quadratic and similar for both countries).

In interpreting the figure, note that PA implements equal sharing (i.e. $\alpha=0.5$ ). Therefore, we know that PA implements the efficient allocation vector. Nevertheless, this efficient allocation vector is not sustainable for all levels of river flow. Figures 3 and 4 show that in years with low or high river flow, one of the two countries has an incentive to defect from the agreement, depending on the type of transfer vector used. This incentive is even higher for FD allocations, but note that $\mathrm{FD}$, like FU, is not generally efficient.

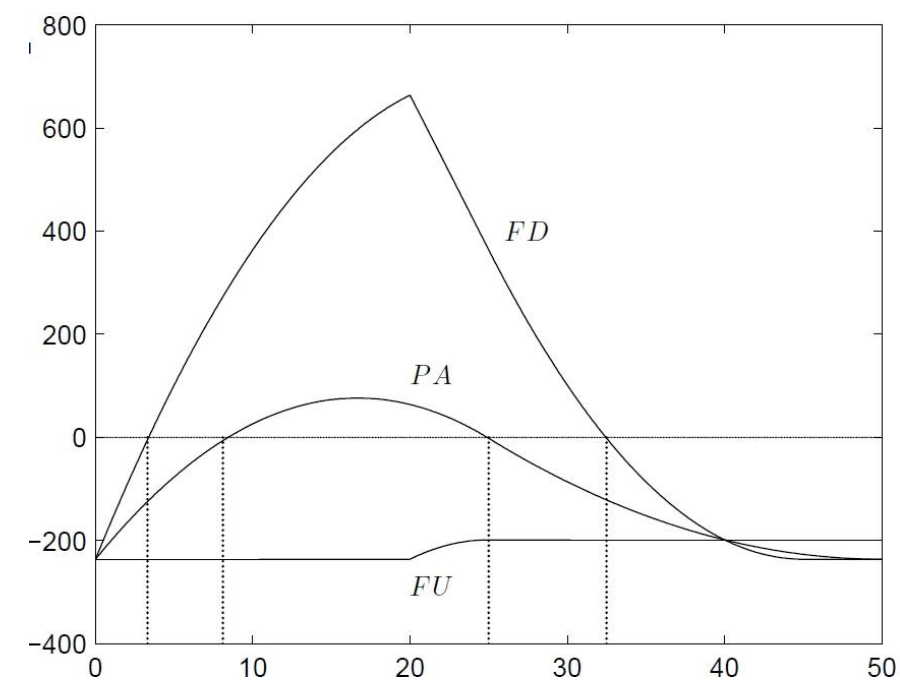

Figure 3: Reproduced from Ansink and Ruijs ( 2008, Figure 2, panel a). Incentive to defect (i.e. the increase in expected utility upon defection) to country 1 with constant transfers. 


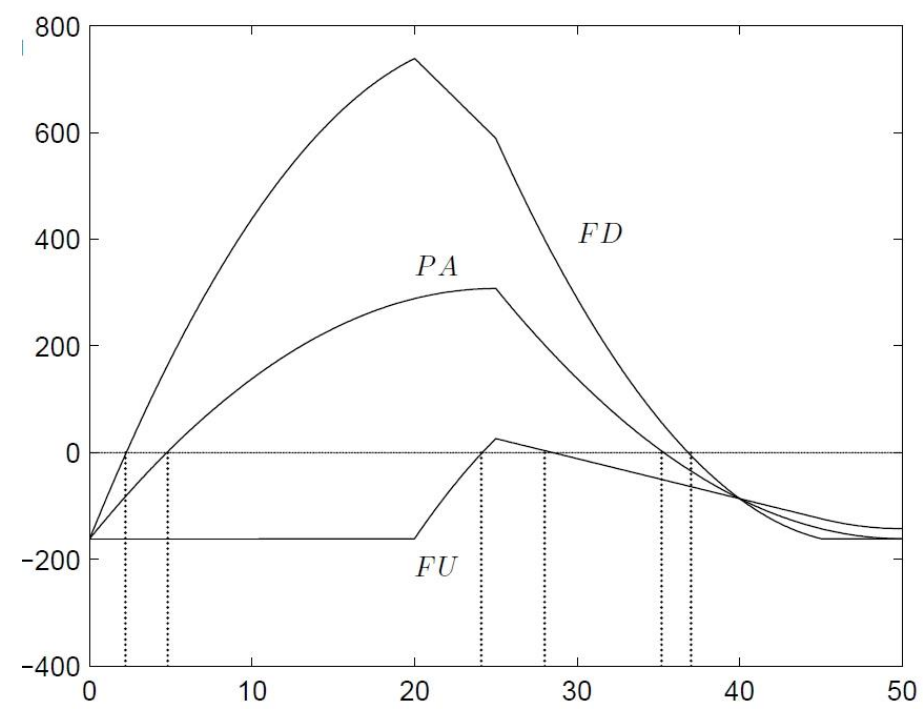

Figure 4: Reproduced from Ansink and Ruijs ( 2008, Figure 2, panel b). Incentive to deviate (i.e. the increase in expected utility upon defection) to country 2 with flexible transfers.

This repeated game clearly demonstrates that simple sharing rules do not generally lead to sustainable allocations. To assess whether other water allocation vectors can improve sustainability, Ansink and Houba (2013) generalize this repeated in various directions. Most importantly, they do not limit themselves to simple sharing rules only. Instead they assess which solution is sustainable under the widest range of possible realizations of river flow, focusing on very general subsets of solutions. The main result is a Folk theorem for river sharing problems that is applied to the subset of so-called 'individually rational' agreements, which we present here in a simplified form.

Result 3 For any discount factor $\delta>\underline{\delta}$ any agreement can be sustained under the restriction that no agent receives less than his minmax value.

The threshold discount factor $\underline{\delta}$ depends, in a fairly straightforward way, on the transfer vector and expected benefits of water use. The authors proceed to assess threshold discount factors for which other, more restrictive, subsets of agreements can be sustained in equilibrium. These subsets include simple sharing rules as assessed by Ansink and Ruijs (2008), Nash-bargaining solutions, and renegotiation-proof equilibria.

Figure 5 illustrates how these results relate to each other in a simplified setting which requires two assumptions:

Assumption 2 The density function of river flow is simplified to two possible realizations of river flow $\left(e_{1}, e_{2}\right)$, high flow $\left(e_{1}^{H}, e_{2}^{H}\right)$ with probability $p$ and low flow $\left(e_{1}^{L}, e_{2}^{L}\right)$ with probability $1-p$. 
Assumption 3 The agreement maximizes utilitarian welfare so that $x_{1}^{c}\left(e_{1}, e_{2}\right)=x_{1}^{*}\left(e_{1}, e_{2}\right)$ and $x_{2}^{c}\left(e_{1}, e_{2}\right)=x_{2}^{*}\left(e_{1}, e_{2}\right)$.

The figure is drawn in transfer-space, showing which combinations of monetary transfers, under low and high flow, provide sustained cooperation. Parameter values used to draw the figure are $\delta=0.9, p=0.5,\left(e_{1}^{L}, e_{2}^{L}\right)=(3,1),\left(e_{1}^{H}, e_{2}^{H}\right)=(5,3)$, and $b_{i}\left(x_{i}\right)=-x_{i}^{2}+10 x_{-} i$ for $i=1,2$.

One interpretation of Figure 5 is that restricting the full set of agreements comes at a cost in the form of a higher threshold discount factor for which the agreement can be sustained. In general, the smaller the subset, the higher this cost. One can see that the set of simple sharing rules that can be sustained in equilibrium is small, indicating their lack of sustainability in general. The overall message of this figure is quite positive. Many solutions to the river sharing problem can be sustained in equilibrium, even with variable river flow.

Obviously, this result depends on the level of the discount factor $\delta$ and Ansink and Houba (2013) provide alternative interpretations of their results in which they asses, given $\delta$, which solutions can be sustained in equilibrium. Using this interpretation, an interesting result is that repeated interaction tends to favor downstream agents. This result may seem counter-intuitive, but it does explain empirical observations on downstream states managing to negotiate a substantial share of upstream river water (Katz and Moore, 2011). The related result focuses on the so-called downstream incremental distribution. This solution, introduced by Ambec and Sprumont (2002) and also discussed in Section 6, implements the efficient water allocation vector $x^{*}$. To understand the associated transfer vectors, denote by $t_{j<i}^{m}=\sum_{j<i} t_{j}^{m}$ the total minimal (i.e. superscript $m$ ) compensation to the set of countries $(1,2, \ldots, i-1)$ upstream of agent $i$. The transfer vector is such that each upstream set of countries receives its minimal compensation $t_{j<i}^{m}$. As a result, the gains from cooperation are assigned as far downstream as possible, only constrained by the minimal compensations to upstream agents. The result is as follows (Ansink and Houba, 2013):

Result 4 At the lowest possible threshold on the discount factor, only the downstream incremental distribution can be sustained and this distribution remains sustainable for higher discount factors. 


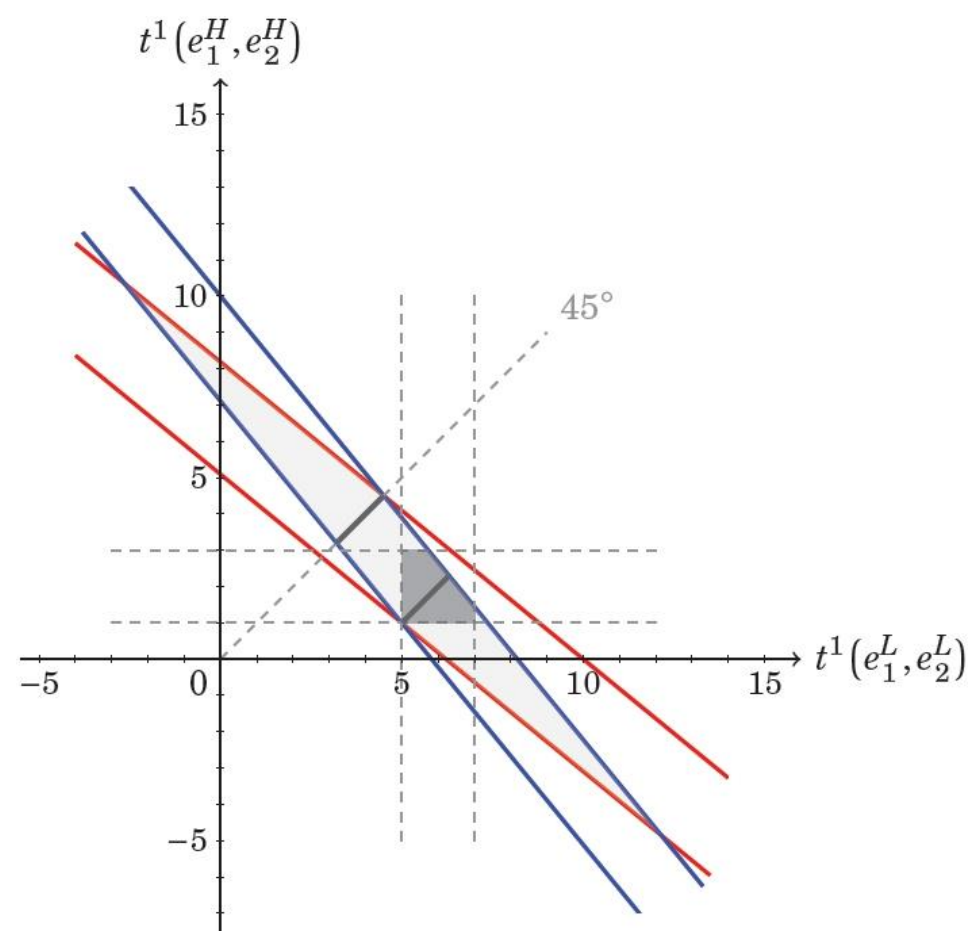

Figure 5: Reproduced from Ansink and Houba ( 2013, Figure 3). Combinations of transfers that provide sustained cooperation including restrictions imposed by the subsets of agreements. The dark-shaded segment on the $45^{\circ}$-line through $(0,0)$ displays the subset of simple sharing rules. The small shaded polygon displays the subset of individually rational agreements. The dark-shaded segment on the $45^{\circ}$-line through $(5,1)$ displays the subset of Nash-bargaining agreements that coincides with the subset of renegotiation-proof agreements.

One other paper that studies the sustainability of the downstream incremental distribution is by Ambec et al. (2013). In addition to this solution, they assess the sustainability of various other solutions, again by assessing which solution is sustainable under the widest range of possible realizations of river flow. Specifically they assess fixed water allocation vectors, including the full set of incremental distributions. The downstream incremental distribution is one extreme solution in this set. The related extreme version is the upstream incremental distribution. This solution is such that each downstream set of countries receives its minimal compensation $t_{j>i}^{m}$. As a result, the gains from cooperation are assigned as far upstream as possible, only constrained by the minimal compensations to downstream agents. Note that the transfer vector is constant in the sense that transfers are based on the expected benefits of river flow. Their main result is as follows:

Result 5 Of all simple sharing rules with fixed allocations and constant transfers, the upstream incremental distribution is the most sustainable solution.

The intuition of this result is that, similar to the setting of Ansink and Ruijs (2008), upstream countries have the highest incentive to deviate, as was illustrated in Figure 3. Since the upstream 
incremental distribution is efficient and gives the highest transfers possible to the upstream countries, this solution simultaneously minimizes the incentives to deviate.

The difference between Results 4 and 5 is that in a static game like Ambec et al. (2013), the incentive to defect lies only with upstream countries. In dynamic games like Ansink and Houba (2013), this incentive to defect switches to the downstream country, since the order of events in the stage game makes punishment of downstream countries upon defection easier compared to punishment of upstream countries. To make solutions sustainable, the country with the highest incentive to deviate should be bribed not to defect. This explains why, in a static setting, solutions that assign a large share of the surplus to upstream countries are most sustainable. The reverse holds in a dynamic setting.

This last result is confirmed in an alternative implementation of the downstream incremental distribution by Ambec and Ehlers (2008a). Ambec and Ehlers (2008a) propose a simple alternating-offer bargaining model, in which priority is given "lexicographically to the most downstream user". Given a set of countries $\{1,2, \ldots, n\}$, country $n$ proposes a solution (i.e. a water allocation vector and a monetary transfer vector) to the other countries. If all accept, this solution is implemented. If any country declines the proposed solution, country $n$ receives $x_{n}=$ $e_{n}$ and $t_{n}=0$, and player $n-1$ proposes a solution, etc. Ambec and Ehlers (2008a) show that the unique subgame-perfect equilibrium of this game implements the downstream incremental distribution.

Up to here, we analyzed sustainable solutions to the river sharing problem that included all river basin countries. It is, however, quite likely that only a subset of countries cooperates. Ansink et al. (2012) used a coalition model to analyze this option, by assessing the size and sustainability of coalitions that allocate water optimally amongst the coalition members. They found the following negative result:

Result 6 In the river sharing problem, coalitions of size two and three are sustainable, but coalitions of at least four agents are not necessarily sustainable.

Apparently, large sustainable coalitions should not be expected in transboundary river basins. The driving force behind this result is the absence of property rights in the river so that any water that is passed on to a downstream coalition member can be seized by an intermediate country that is not in the coalition. This result confirms an earlier observation in Section 4.1 that most agreements are not basin-wide but usually involve only two (maybe three) countries.

Ambec and Ehlers (2008b) also assessed coalitions in the river sharing problem, but using a cooperative approach which is further discussed in Section 6. Most of their results imply grand 
coalitions except for a minor remark in which they find that the grand coalition is not necessarily required to obtain an efficient allocation (Ambec and Ehlers, 2008b, Remark 6).

\section{Fairness}

Next to efficiency and sustainability, the third and final key objective of transboundary river management is fairness. Needless to say, fairness is a subjective concept and should be assessed with care. The economics discipline usually considers fairness only in the context of social welfare. Originating from welfare economics, this concept denotes the use of welfare functions that aim to maximize some function of agents' (weighted) utilities over a feasible set of welfare distributions. Related to this is the analysis of the properties of welfare functions. In the context of the river sharing problem, this analysis focuses on the properties of distribution rules for the utility derived from using river water.

This analysis of properties is usually done using the axiomatic approach (see e.g. Thomson, 2001, for an overview), a method within cooperative game theory. In line with the above description of studying fairness in the context of social welfare, recent axiomatic studies (cf. Ambec and Sprumont, 2002; Ambec and Ehlers, 2008b; Khmelnitskaya, 2010; Van den Brink et al., 2012; Béal et al., 2012) model river sharing as a cooperative game, where the axioms are imposed on the distribution of welfare to the agents. Recently, Van den Brink et al. (2014) argued that, instead, the axioms should be imposed directly on the allocation of welfare derived from water use, which allows a closer link between the axioms and actual water allocation. In response, Ansink and Weikard (2013) took this argument one step further and imposed axioms directly on the allocation of water. This last approach has the consequence that countries' benefit functions are ignored. This has the advantage of avoiding some difficulties in implementing cooperative solutions for water allocation, identified by Dinar et al. (1992). A disadvantage is obviously that efficiency is ignored, since, by ignoring benefit functions, we end up in the river claims problem.

Whether the axioms are imposed on welfare distribution in a cooperative game, on the allocation of benefits of water use, or on water allocation itself may depend on the characteristics of specific river sharing problems. In some river basins, countries may prefer to allocate physical units of water (cf. Dinar and Nigatu, 2013), while in other basins countries may prefer to allocate the welfare derived from water use (i.e. 'benefit sharing'), although essentially there is not much difference between the two. Note that in the vast majority of reported negotiations on river water, the subject of negotiation is actual physical units of water, rather than the benefits derived from water use (Beach et al., 2000). In line with this observation Wolf (1999) argues that

"In practice, economic criteria have influenced water allocations only in the exception." 
Of course, this statement ignores economic criteria that are not based on benefit functions, including recommendations from the river claims problem. Furthermore, even though benefit functions may be ignored during the initial allocation of river water, once this allocation is established and property rights are mutually acknowledged, agents can decide to engage in water trade if there are unexploited welfare gains to be made.

Below, we present a selection of results from the small literature that applies the axiomatic approach to the river sharing problem, which is also reviewed by Béal et al. (2013). Some solutions that were introduced in Section 5.2 will return here, emphasizing the link between non-cooperative and cooperative approaches to the river sharing problem. Making this link practical, the axiomatic approach can be easily put to use in negotiations on river sharing because the axioms used in the axiomatic approach can often be interpreted quite naturally as describing characteristics of a negotiation procedure. Also, by satisfying desirable axioms, solutions are more likely to be acceptable to the countries involved. Such procedures can either be implemented by the negotiating countries themselves, by the members of a joint river basin committee, or perhaps even by a third party that is called in to support countries in their negotiations on river water (Ansink and Weikard, 2009).

We will discuss solution both for the river sharing problem and for the river claims problem as a special case.

\subsection{Axiomatic solutions to the river sharing problem}

The literature on the axiomatic approach to the river sharing problem started with a remarkable result by Ambec and Sprumont (2002), who translated the ATS and UTI principles from international water law into axioms. The axiom based on ATS defines so-called Core Lower Bounds, based on the welfare distribution $\pi=\left(\pi_{i}\left(x_{1}, t_{1}\right), \pi_{2}\left(x_{2}, t_{2}\right), \ldots, \pi_{n}\left(x_{n}, t_{n}\right)\right)$.

Axiom 1 (Core Lower Bounds) For each river sharing problem $\langle N, e, b\rangle$ we have $\sum_{i \in S} \pi_{i}\left(x_{i}, t_{i}\right) \geq \sum_{i \in S} b_{i}\left(x_{i}\right)$ for each subset of countries $S \subset N$.

This axiom says that no set of countries should have a joint utility lower than the welfare that these countries can secure by optimally using their own endowments. The axiom based on UTI defines so-called Aspiration Upper Bounds

Axiom 2 (Aspiration Upper Bounds) For each river sharing problem $\langle N, e, b\rangle$ we have $\sum_{i \in S} \pi_{i}\left(x_{i}, t_{i}\right) \leq \sum_{i \in S} b_{i}\left(\sum_{j \leq i} x_{j}\right)$ for each subset of countries $S \subset N$.

This axiom says that no set of countries should have a joint utility higher than the welfare that these countries could secure by optimally using all water generated upstream in addition to their own endowments. 
Ambec and Sprumont (2002) provide the following characterization result.

Result 7 The downstream incremental distribution is the only solution that satisfies Core Lower Bounds and Aspiration Upper Bounds.

The two principles of ATS and UTI are complete opposites in terms of the allocation of water, and the downstream incremental distribution manages to settle a compromise between these opposing principles. As discussed in Section 5.2, the downstream incremental distribution assigns the gains from cooperation as far downstream as possible, only constrained by the minimal compensations to upstream agents. As a result, this solution can easily be criticized as being unrealistic or having no practical value. Nevertheless, as demonstrated by Result 4 and subsequent text, this extreme solution is a plausible outcome of two different non-cooperative games (Ambec and Ehlers, 2008a; Ansink and Houba, 2013) and is even the most sustainable solution when dynamic considerations are taken into account. Note that Result 7 was obtained by Ambec and Sprumont (2002) for the case of non-satiated benefit functions. Ambec and Ehlers (2008b) generalized this result for the case of satiated benefit functions, so that Result 7 is quite general.

Van den Brink et al. (2012) introduced a more general axiomatization of solutions to the river sharing problem by allowing for more general river systems (i.e. multiple sources and sinks) and by replacing axioms based on ATS and UTI with an axiom based on the TIBS principle. The TIBS principle refers to the Territorial Integration of all Basin States, interpreted by Moes (2013) as follows.

"Water of an international watercourse belongs to all basin states combined, no matter where it enters the watercourse. Each riparian state is entitled to a reasonable and equitable share in the optimal use of the waters of the international watercourse. "

Moes (2013) stresses that this principle assigns reasonable and equitable shares and, importantly, that it demands that the water is allocated efficiently, thereby fixing the water allocation vector.

The translation of this principle into an axiom is as follows. Assume that there are two coalitions. One upstream coalition $S^{i}$, whose most downstream member is country $i \neq n$ and one downstream coalition $T^{i}=N\left\{S^{i}\right\}$ consisting of all other countries. Each coalition's members cooperate by choosing efficient water allocation vectors within their coalition. Denote by $\pi\left(S^{i}\right)$ and $\pi\left(T^{i}\right)$ the joint utility of all members of coalition $S^{i}$ and $T^{i}$ respectively. The $\alpha$-TIBS Fairness axiom pertains to the distribution of the surplus when the two coalitions merge, and proposes that this surplus is distributed proportionally to the coalitions' weights, these weights being the sum of the coalition members' weights $\alpha_{i}$ with $\sum_{i \in N} \alpha_{i}=1$. 
Axiom 3 (a-TIBS Fairness) For each river sharing problem $\langle N, e, b\rangle$ and for any agent $i \neq$ $n$ we have

$$
\frac{\sum_{j \in S^{i}}\left(\pi_{i}\right)-\pi_{i}\left(S^{i}\right)}{\sum_{j \in T^{i}}\left(\pi_{i}\right)-\pi_{i}\left(T^{i}\right)}=\frac{\sum_{j \in S^{i}} \alpha_{i}}{\sum_{j \in T^{i}} \alpha_{i}}
$$

For every specific vector of weights $\alpha=\left(\alpha_{1}, \alpha_{2}, \ldots, \alpha \_n\right)$, the requirement of $\alpha$-TIBS Fairness characterizes a particular solution to the river sharing problem. This set of solutions is called 'weighted hierarchical solutions'. For the case of a linear river, as in our simple river sharing problem, Van den Brink et al. (2012) demonstrate the following results.

Result 8 A solution to the river sharing problem satisfies Efficiency and $\alpha$-TIBS Fairness if and only if it is a weighted hierarchical solution with weights vector $\alpha$.

Result 9 The weighted hierarchical solution with $\alpha_{n}=1$ corresponds to the downstream incremental distribution. The weighted hierarchical solution with $\alpha_{1}=1$ corresponds to the upstream incremental distribution. The weighted hierarchical solution with $\alpha_{i}=1 / n \forall i \in N$ corresponds to the average hierarchical solution, which features an egalitarian distribution of the cooperative surplus.

Clearly, weighted hierarchical solutions can be seen as compromise solutions between the up- and downstream incremental distributions. In practical terms, the choice of a particular vector of weights $\alpha$ is sufficient to determine a solution according to the TIBS principle.

In a different paper, Van den Brink et al. (2014) weaken some assumptions on the benefit function used by Ambec and Sprumont (2002). Specifically, they replace differentiability by continuity and strict concavity by concavity (allowing for satiation). In addition, Van den Brink et al. (2014) weaken the two axioms used by Ambec and Sprumont (2002). Specifically, they replace Core Lower Bounds and Aspiration Upper Bounds by Efficiency, a Lower-Bound Property (stating that each country receives at least a utility equal to its benefit of using no water at all), and a Weak Aspiration Level Property (stating that each country receives at most the utility it would receive if it could use all river water, independent of the availability constraint (2)). Furthermore, Van den Brink et al. (2014) introduce two basic independence axioms, whose interpretation needs no further explanation.

Axiom 4 (Independence of downstream benefits) For each river sharing problem $\langle N, e, b\rangle$ and its related problem $\left\langle N, e, b^{\prime}\right\rangle$ such that $b_{j}=b_{j}^{\prime}$ for all $j \leq i$, we have $x_{i}(<N, e, b\rangle$ )$=x_{i}\left(<N, e, b^{\prime}>\right)$. 
Axiom 5 (Independence of upstream benefits) For each river sharing problem $\langle N, e, b\rangle$ and its related problem $\left\langle N, e, b^{\prime}>\right.$ such that $b_{j}=b_{j}^{\prime}$ for all $j \geq i$, we have $x_{i}(<N, e, b>)=$ $x_{i}\left(<N, e, b^{\prime}>\right)$.

Van den Brink et al. (2014) prove two main results. To understand Result 11 below, which we will come back to in Section 6.2, we first introduce the UTI incremental distribution. This solution implements the efficient water allocation vector $x^{*}$. The associated monetary transfer vector $t$ is such that each downstream set of countries is fully compensated for any water that they do not use due to the implementation of $x^{*}$, thereby fully reflecting the UTI principle. Unlike the downstream incremental distribution, transfers are not constrained by minimal compensations to upstream agents. As a result of this extreme transfer vector, it is straightforward to see that upstream countries are better off defecting from this solution. As a result the UTI incremental distribution is not likely to be sustainable.

Result 10 The downstream incremental distribution is the only solution that satisfies Efficiency, the Lower Bound Property, the Weak Aspiration Level Property and Independence of Downstream Benefits.

Result 11 The UTI incremental distribution is the only solution that satisfies Efficiency, the Lower Bound Property, the Weak Aspiration Level Property and Independence of Upstream Benefits.

Both solutions will also be characterized in the next section in the setting of the river claims problem.

\subsection{Axiomatic solutions to the river claims problem}

In the special case of the river claims problem, the axiomatic approach is naturally based on conventional claims problems (also known as bankruptcy problems), introduced by O'Neill (1982) and surveyed by Thomson (2003). Two differences are that, in the claims problem, the agents are not ordered and that there is just one resource to be allocated to the agents, while in the river claims problem, agents are ordered, and each agent has an endowment that can be allocated. The river claims problem was introduced by Ansink and Weikard (2012) and they were also the first to offer solutions to this problem using the axiomatic approach. Specifically, Ansink and Weikard (2012) proposed a class of 'sequential sharing rules' that allowed solving a river claims problem sequentially. Starting upstream with country $i=1$, the river claims problem is divided into a sequence of two-player reduced river claims problems $\left\langle\left\{i, T^{i}\right\}, E_{i},\left\{c_{i}, c_{T^{i}}\right\}>\right.$, in which, like before, $T^{i}$ denotes the set of countries downstream of $i$, and this set is considered as a single player. Since this reduced problem abstracts away from ordering and has only one endowment $E_{i}$ 
(i.e. the available water to $i$ that has to be distributed between $i$ and the set of its downstream countries), standard allocation rules from conventional claims problems can be applied to any reduced problem. This can be done recursively, using the same allocation rule, which solves the river claims problem. The following result characterizes the class of sequential sharing rules that follows this procedure, using three (arguably) weak axioms: Only n's Excess Claim Matters (stating that allocation of upstream water is independent of the part of agent $n$ 's claim that can be satisfied with its own endowment $e_{n}$.), No Advantageous Downstream Merging (stating that allocation of upstream water is independent of merging claims and endowments of agents $n-1$ and $n$ ), and Upstream Consistency (stating that when the most upstream player leaves with his allocation, the truncated game gives the same allocation as the original game to the remaining players).

Result 12 A sharing rule for river claims problem $\langle N, e, c\rangle$ satisfies Only n's Excess Claim Matters, No Advantageous Downstream Merging and Upstream Consistency if and only if it is a sequential sharing rule.

The paper proceeds to provide characterizations of the sequential sharing rule based on proportional sharing.

In a sequel paper, Ansink and Weikard (2013) demonstrate that the downstream incremental distribution and the UTI incremental distribution also fall in the class of sequential sharing rules and they provide the following results, using the notion of Priority rules, introduced by Moulin (2000).

Definition 1 (Priority rule) The Priority rule B for a claims problem with ordered agents $<N, e, c>$ allocates water such that for all $i, j \in N$ with $i<j$, if $B_{j}(N, e, c)>0$, then $B_{i}(<N, e, c>)=c_{i}$.

Definition 2 (Reverse Priority rule) The Reverse Priority rule B for a claims problem with ordered agents $\langle N, e, c\rangle$ allocates water such that for all $i, j \in N$ with $i\left\langle j\right.$, if $\left.B_{j}(N, e, c)\right\rangle$ 0 , then $\left.B_{j}(<N, e, c\rangle\right)=c_{j}$.

Result 13 On the class of river claims problems, the downstream incremental distribution coincides with the sequential sharing rule based on the Priority rule.

Result 14 On the class of river claims problems, the UTI incremental distribution coincides with the sequential sharing rule based on the Reverse Priority rule.

Both solutions are characterized by Ansink and Weikard (2013) using the three characterizing axioms of sequential sharing rules plus one axiom that reflects the nature of the Priority rule and its inverse. Both solutions are also characterized by Van den Brink et al. (2014) using an appropriate 
conversion of the axioms used in Results 10 and 11 to the domain of river claims problems (e.g. Independence of Upstream Benefits being replaced by Independence of Upstream Claims.

Finally, Ansink and Weikard (2013) introduce four Composition axioms that pertain to the possibility that after its initial allocation, the available amount of the resource turns out to be different from what was expected. As a result, these axioms are closely related to the hydrological characteristics of river flow, as discussed in Section 5.1. The axioms are derived from Composition axioms for the conventional claims problem, and tailored to the setting of river sharing. Without going in to the details of each axiom, we present the following main result.

Result 15 On the class of river claims problems, the downstream incremental distribution is the only solution to satisfy all four Composition axioms.

Note that, on the class of river claims problems, the downstream incremental distribution implements the ATS principle (or Harmon Doctrine) by allocating each country its own endowment. By Result 15 this solution is, from an axiomatic perspective, the most sustainable solution with respect to variability and uncertainty of river flow. This result nicely complements the results on sustainability presented and discussed in Section 5.2.

\section{Summary}

This chapter has reviewed the economics of transboundary river management by assessing three key objectives: efficiency, sustainability, and fairness. Using the river sharing problem as a simple model allowed us to assess each of these objectives separately as well as to make various links between them. The overview of the literature in this chapter does not give rise to specific conclusions in terms of (in)compatibility of key objectives. We can summarize, however, the contributions that the analysis of the river sharing problem has made to understanding the economics of transboundary river management. This summary is as follows. Irrespective of the perspective (efficiency, sustainability, fairness), or methodology employed (cooperative, non-cooperative), solutions to the river sharing problem come down to the implementation of the efficient water allocation vector and the subsequent choice of an appropriate monetary transfer vector. This simple observation highlights, perhaps, the obsession of economists with efficient allocations. By using the term 'appropriate', it also highlights that no specific recommendation emerges from this chapter in terms of the distribution of the surplus from cooperation, although one could argue that the downstream incremental distribution has a dominant position in the literature. Recommendations on monetary transfers will inevitably depend on specific conditions in specific river basins. 
Our summary contrasts with some of the evidence on river sharing where efficiency is not often employed or perceived as a key objective of transboundary river management. Apparently, economic factors receive only modest priority compared to other factors, including the political aspects of water management. Also, most of the work reviewed in this chapter ignores many other hydrological (as well as economic) aspects that can be crucial in specific case studies and has received much attention in mainly applied work. These include other river geographies, return flows, the link between water quantity and quality, the link between water and energy, conjunctive groundwater-surface water management, ecological aspects, etc. Ignoring these aspects allowed us to analyze the efficiency, sustainability, and fairness of transboundary river water allocation with just a few variables and parameters.

\section{References}

Adams, G., G. Rausser, and L. Simon (1996). Modelling multilateral negotiations: An application to California water policy. Journal of Economic Behavior and Organization 30(1), 97-111.

Ambec, S., A. Dinar, and D. McKinney (2013). Water sharing agreements sustainable to reduced flows. Journal of Environmental Economics and Management 66(3), 639-655.

Ambec, S. and L. Ehlers (2008a). Cooperation and equity in the river sharing problem. In A. Dinar, J. Albiac, and J. Sánchez-Soriano (Eds.), Game Theory and Policy-making in Natural Resources and the Environment. London: Routledge.

Ambec, S. and L. Ehlers (2008b). Sharing a river among satiable agents. Games and Economic Behavior 64(1), 35-50.

Ambec, S. and Y. Sprumont (2002). Sharing a river. Journal of Economic Theory 107(2), 453-462.

Ansink, E., M. Gengenbach, and H.-P. Weikard (2012). River sharing and water trade. FEEM Working Paper 017.2012.

Ansink, E. and H. Houba (2012). Market power in water markets. Journal of Environmental Economics and Management 64(2), 237-252.

Ansink, E. and H. Houba (2013). Sustainable agreements on stochastic river flow. Tinbergen Institute Discussion Paper 2013/182.

Ansink, E. and A. Ruijs (2008). Climate change and the stability of water allocation agreements. Environmental and Resource Economics 41(2), 249-266.

Ansink, E. and H.-P. Weikard (2009). Contested water rights. European Journal of Political Economy 25(2), 247-260.

Ansink, E. and H.-P. Weikard (2012). Sequential sharing rules for river sharing problems. Social Choice and Welfare 38(2), 187-210.

Ansink, E. and H.-P. Weikard (2013). Composition properties in the river claims problem. Tinbergen Institute Discussion Paper 2013/199.

Barrett, S. (1994). Conflict and cooperation in managing international water resources. World Bank Policy Research Working Paper 1303.

Bates, B., Z. Kundzewicz, S. Wu, and J. Palutikof (2008). Climate change and water. Intergovernmental Panel on Climate Change, Technical Paper VI. 
Beach, H., J. Hammer, J. Hewitt, E. Kaufman, A. Kurki, J. Oppenheimer, and A. Wolf (2000). Transboundary Freshwater Dispute Resolution: Theory, Practice, and Annotated References. Tokyo: United Nations University Press.

Béal, S., A. Ghintran, E. Rémila, and P. Solal (2013). The river sharing problem: A survey. International Game Theory Review 15(3), 1340016.

Béal, S., E. Rémila, and P. Solal (2012). The sequential equal surplus division for sharing a river. MPRA Paper No. 37346, Munich Personal RePEc Archive.

Bennett, L., C. Howe, and J. Shope (2000). The interstate river compact as a water allocation mechanism: Efficiency aspects. American Journal of Agricultural Economics 82(4), 1006-1015.

Bennett, L., S. Ragland, and P. Yolles (1998). Facilitating international agreements through an interconnected game approach: The case of river basins. In R. Just and S. Netanyahu (Eds.), Conflict and Cooperation on Transboundary Water Resources, pp. 61-85. Boston, MA: Kluwer Academic Publishers.

Bhaduri, A. and E. Barbier (2008). International water transfer and sharing: The case of the Ganges river. Environment and Development Economics 13(1), 29-51.

Bjornlund, H. and J. McKay (2002). Aspects of water markets for developing countries: Experiences from Australia, Chile, and the US. Environment and Development Economics 7(4), 769-795.

Carey, J., D. Sunding, and D. Zilberman (2002). Transaction costs and trading behavior in an immature water market. Environment and Development Economics 7(4), 733-750.

Carraro, C., C. Marchiori, and A. Sgobbi (2007). Negotiating on water: Insights from non-cooperative bargaining theory. Environment and Development Economics 12(2), 329-349.

Chong, H. and D. Sunding (2006). Water markets and trading. Annual Review of Environment and Resources 31(1), 239-264.

Daoudy, M. (2008). Hydro-hegemony and international water law: Laying claims to water rights. Water Policy 10(S2), 89-102.

De Stefano, L., J. Duncan, S. Dinar, K. Stahl, K. Strzepek, and A. Wolf (2012). Climate change and the institutional resilience of international river basins. Journal of Peace Research 49(1), 193-209.

Dettinger, M. and H. Diaz (2000). Global characteristics of stream flow seasonality and variability. Journal of Hydrometeorology 1(4), 289-310.

Dinar, A. and G. Nigatu (2013). Distributional considerations of international water resources under externality: The case of Ethiopia, Sudan and Eypt on the Blue Nile. Water Resources and Economics 2-3, 116.

Dinar, A., A. Ratner, and D. Yaron (1992). Evaluating cooperative game theory in water resources. Theory and Decision 32(1), 1-20.

Dinar, A., M. Rosegrant, and R. Meinzen-Dick (1997). Water allocation mechanisms: Principles and examples. World Bank Policy Research Working Paper 1779.

Dinar, S. (2006). Assessing side-payment and cost-sharing patterns in international water agreements: The geographic and economic connection. Political Geography 25(4), 412-437.

Dinar, S. (2007). International Water Treaties: Negotiation and Cooperation along Transboundary Rivers. London: Routledge.

Dombrowsky, I. (2007). Conflict, Cooperation and Institutions in International Water Management. Cheltenham: Edward Elgar.

Gastélum, J., J. Valdés, and S. Stewart (2009). A decision support system to improve water resources management in the Conchos basin. Water Resources Management 23(8), 1519-1548.

Gisser, M. and D. A. Sanchez (1980). Competition versus optimal control in groundwater pumping. Water Resources Research 16(4), 638-642.

Gleick, P. H. (1994). Water, war \& peace in the middle east. Environment 36(3), 6-42. 
Hanemann, W. M. (2006). The economic conception of water. In P. Rogers, M. Llamas, and L. Martinez-Cortina (Eds.), Water Crisis: Myth or Reality. London: Taylor \& Francis.

Holden, P. and M. Thobani (1996). Tradable water rights: A property rights approach to resolving water shortages and promoting investment. World Bank Policy Research Working Paper 1627.

Houba, H. (2008). Computing alternating offers and water prices in bilateral river basin management. International Game Theory Review 10(3), 257-278.

Houba, H., K. Pham Do, and X. Zhu (2013). Saving a river: a joint management approach to the Mekong River Basin, Environment and Development Economics 18(S1), 93-103.

Houba, H., G. Van der Laan, and Y. Zeng (2014). Asymmetric Nash solutions in the river sharing problem. Forthcoming in Strategic Behavior and the Environment.

Katz, D. and M. Moore (2011). Dividing the waters: An empirical analysis of interstate compact allocation of transboundary rivers. Water Resources Research 47(6), W06513.

Khmelnitskaya, A. (2010). Values for rooted-tree and sink-tree digraph games and sharing a river. Theory and Decision 69(4), 657-669.

Kilgour, D. and A. Dinar (1995). Are stable agreements for sharing international river waters now possible? World Bank Policy Research Working Paper 1474.

Kilgour, D. and A. Dinar (2001). Flexible water sharing within an international river basin. Environmental and Resource Economics 18(1), 43-60.

Krzysztofowicz, R. (2001). The case for probabilistic forecasting in hydrology. Journal of Hydrology 249(1-4), 2-9.

Lekakis, J. (1998). Bilateral monopoly: A market for intercountry river water allocation. Environmental Management 22(1), 1-8.

Milly, P., K. Dunne, and A. Vecchia (2005). Global pattern of trends in streamflow and water availability in a changing climate. Nature 438(7066), 347-350.

Moes, N. (2013). Cooperative Decision Making in River Water Allocation Problems. PhD Thesis, VU University Amsterdam.

Montanari, A. and G. Grossi (2008). Estimating the uncertainty of hydrological forecasts: A statistical approach. Water Resources Research 44(12), W00B08.

Mostert, E. (2003). Conflict and cooperation in international freshwater management: A global review. International Journal of River Basin Management 1(3), 1-12.

Moulin, H. (2000). Priority rules and other asymmetric rationing methods. Econometrica 68(3), 643-684.

Negri, D. H. (1989). The common property aquifer as a differential game. Water Resources Research 25(1), 9-15.

NWA (1959). Agreement between the government of the United Arab Republic and the government of Sudan for the full utilization of the Nile waters. Available at http://www.transboundarywaters.orst.edu/.

O’Neill, B. (1982). A problem of rights arbitration from the Talmud. Mathematical Social Sciences 2(4), 345-371.

Ostrom, E. (1990). Governing the Commons: The Evolution of Institutions for Collective Action. Cambridge: Cambridge University Press.

Provencher, B. and O. Burt (1993). The externalities associated with the common property exploitation of groundwater. Journal of Environmental Economics and Management 24(2), 139-158.

Richards, A. and N. Singh (2001). No easy exit: Property rights, markets, and negotiations over water. International Journal of Water Resources Development 17(3), 409-425.

Rosegrant, M. and H. Binswanger (1994). Markets in tradable water rights: Potential for efficiency gains in developing country water resource allocation. World Development 22(11), 1613-1625. 
Rubio, S. and B. Casino (2003). Strategic behavior and efficiency in the common property extraction of groundwater. Environmental and Resource Economics 26(1), 73-87.

Salman, S. (2007). The Helsinki Rules, the UN Watercourses Convention and the Berlin Rules: Perspectives on international water law. International Journal of Water Resources Development 23(4), 625-640.

Thomson, W. (2001). On the axiomatic method and its recent applications to game theory and resource allocation. Social Choice and Welfare 18(2), 327-386.

Thomson, W. (2003). Axiomatic and game-theoretic analysis of bankruptcy and taxation problems: A survey. Mathematical Social Sciences 45(3), 249-297.

Van den Brink, R., A. Estévez-Fernández, G. van der Laan, and N. Moes (2014). Independence of downstream and upstream benefits in river water allocation problems. Social Choice and Welfare 43(1), 173-194.

Van den Brink, R., G. van der Laan, and N. Moes (2012). Fair agreements for sharing international rivers with multiple springs and externalities. Journal of Environmental Economics and Management 63(3), 388-403.

Wang, L., L. Fang, and K. Hipel (2008). Basin-wide cooperative water resources allocation. European Journal of Operational Research 190(3), 798-817.

Wang, Y. (2011). Trading water along a river. Mathematical Social Sciences 61(2), 124-130.

Ward, F. (2013). Forging sustainable transboundary water-sharing agreements: Barriers and opportunities. Water Policy 15(3), 386-417.

Ward, P., W. Beets, L. Bouwer, J. Aerts, and H. Renssen (2010). Sensitivity of river discharge to ENSO. Geophysical Research Letters 37(12), L12402.

Whittington, D., X. Wu, and C. Sadoff (2005). Water resources management in the Nile basin: The economic value of cooperation. Water Policy 7(3), 227-252.

Wirsing, R. and C. Jasparro (2007). River rivalry: Water disputes, resource insecurity and diplomatic deadlock in South Asia. Water Policy 9(3), 231-251.

Wolf, A. (1998). Conflict and cooperation along international waterways. Water Policy 1(2), 251-265.

Wolf, A. (1999). Criteria for equitable allocations: The heart of international water conflict. Natural Resources Forum 23(1), 3-30.

Zeitoun, M. and J. Warner (2006). Hydro-hegemony: A framework for analysis of trans-boundary water conflicts. Water Policy 8(5), 435-460. 